\section{Y. Joulali}

Resident, Department of Neurosurgery,

Hassan II University Hospital, Fes, Morocco

\section{F. Lakhdar}

Professor, Department of Neurosurgery, Hassan II University Hospital, Fes,Morocco

\section{Benzagmout}

Professor, Department of Neurosurgery, Hassan II University Hospital, Fes,Morocco

\section{K. Chakour}

Professor, Department of Neurosurgery, Hassan II University Hospital, Fes,Morocco

\section{Bipin Chaurasia}

Chief Resident, Department of Neurosurgery, Bangabandhu Sheikh Mujib Medical University, Dhaka, Bangladesh

\section{M.F. Chaoui}

Professor, Department of Neurosurgery, Hassan II University Hospital, Fes,Morocco

\author{
Address for correspondence: \\ Y. Joulali , Resident \\ Department of Neurosurgery , \\ Hassan II University Hospital, Fes Moroccco \\ Email: joulali.youssef5@gmail.com
}

Date submitted : 15 July 2019

Date accepted : 30 August 2019

\section{Our institutional experience with Spinal Epidural Abscess}

Spinal epidural abscess is a rare pathology which is manifested by a classic triad of pain, fever and neurological deficit. In most cases, the clinical picture is incomplete which makes its diagnosis difficult. In this retrospective study, we report five cases of spinal epidural abscess treated in the neurosurgery department of Hassan II University Hospital of Fez. Four of our patients were admitted due to spinal cord compression, while one patient was admitted for isolated spinal syndrome without neurological deficit. Fever was present in all our patients, nevertheless no point of entry was identified in the initial assessment.

MRI was performed on emergency basis in all of our patients which demonstrated an extradural hypo intensity on T1WI, hyperintensity on T2WI .It also showed lesions with peripheral enhancement after contrast with gadolinium.

Four of our patients underwent surgical treatment which involved performing a laminectomy/laminotomy with drainage of the abscess, while one patient received medical treatment alone. The evolution was favorable in 4 of our patients while one patient died postoperatively due to severe sepsis.

Key words: spinal epidural abscess, pain, fever, laminectomy, laminotomy

located in posterior aspect of the spinal canal while those from direct source has their locations are in anterior spect of spinal canal. Direct spread from a paraspinal abscess and Vertebral osteomyelitis are also source of abscess. blunt trauma, epidural catheter insertion and postoperative are also source of abscess. MRI plays a decisive role in its diagnosis ( Figure 1).

While antibiotic therapy is the key to its treatment, an early surgical decompression is sometimes necessary to preserve the functional prognosis and to prevent neurological deficits.

We report below the cases of patients admitted for management of spinal epidural abscesses in the neurosurgery department at Hassan II University Hospital of Fez. 


\section{Material and Methods:}

This is retrospective study conducted at Hassan II University Hospital of Fez, of five cases of spinal epidural abscess that were treated in the neurosurgery department between 2004 and 2017.

\section{Results:}

All patients were male with a mean age of 52.4 years, ranging from 18 years to 67 years. Type 2 diabetes was found in two of our patients representing a percentage of $40 \%$ of this cohort. The average admission time was 39.6 days with extremes ranging from 3 to 60 days? Fever and spinal syndrome had been found in all of our patients while the neurological deficit was found in 4 of our patients. Spinal MRI was emergently performed in all of our patients and the thoracic region was the most common location (Table 1).

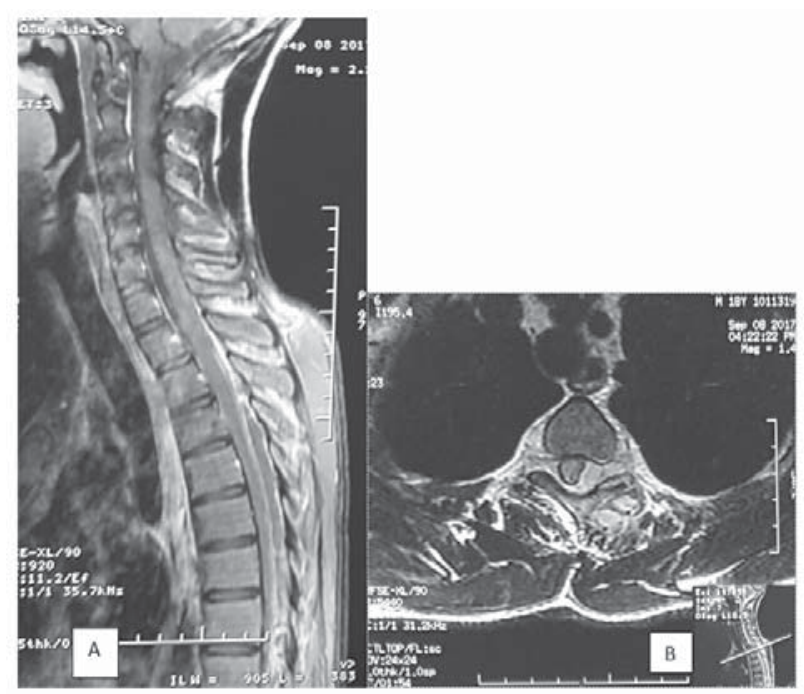

Figure 1 : Sagittal T1 view after contrast (a) and axial view (b) showing an extra-dural collection with peripheral enhancement suggesting an epidural abscess

\begin{tabular}{|l|l|}
\hline Case & Spinal location \\
\hline Patient 1 & Lumber L2-L5 \\
\hline Patient 2 & Cervico-thoracic C4-T4 \\
\hline Patient 3 & Lumber L5-S1 \\
\hline Patient 4 & Thoracic T3-T10 \\
\hline Patient 5 & Cervico-thoraco-lumber \\
\hline
\end{tabular}

Table 1 : Location of SEDA in our series (5 cases)

The surgical indication was retained in 4 of our patients. While 3 of our patients underwent laminectomy one, laminotomy( figure 2)was performed in one of the patient. And yet one patient was treated with medical therapy alone.

All patients were put on triple antibiotics-therapy consisting ofaBetalactam(amoxicillin/C3G), glycopeptide (vancomycin) and aminoglycoside (gentamicin). Moderate strength analgesia and anticoagulant therapy were also added for patients with neurological deficits.

The bacteriological study was negative in 2 cases and Staphylococcus aureus was found in 3 cases. The clinical evolution was marked by an improvement in 3 of our patients. Stabilization of clinical signs was gained in one patient and death in one patient on day three post operation due to overwhelming sepsis

\section{Discussion:}

Spinal epidural abscess is a rare pathology (0.2-2.8 per 10000 person / year), preferentially affecting those over 50 years of age usually in an immunocompromised persons1,9,10,11,12,13,14. The most offending organism being Staphylococcus aureus. ${ }^{3,8,9,15,16}$

Mycobacterium tuberculosis, Streptococcus milleri, Haemophilus parainfluenzae, Brucella species,and Actinomyces israelii are amongst the many other isolates described. Disseminated fungal infections such as cryptococcosis, aspergillosis, and blastomycosis are rare causes and usually arise in immunocompromised patients. Aspergillus species are known to cause spinal epidural abcess in patients with AIDS. ${ }^{13,14,15}$

The described sites of spinal epidural abcess are variable. Only 20\% occur anterior to the spinal cord. Abscesses in the cervical or upper thoracic region are not uncommon. Larger studies, however, describe a preponderance of lower thoracic and lumbar abscesses. The patients with lumbar abscesses may be misdiagnosed as having a herniated lumbar disc. ${ }^{9,13,16}$

Most of the posterior SEDA have a location remote from a site of infection (dental abscess, pharyngitis, skin infection) and is most often associated prior osteomyelitis or spondylodiscitis. ${ }^{2,3,4}$

The classic triad of fever, spinal syndrome and neurological deficits remain unspecific. Heusner described 4 stages of clinical evolution of the spinal epidural abscess5. The 1st stage is characterized by a spinal syndrome and fever, 2nd stage by spinal irritation, the 3rd stage with sensory loss and / or sphincter dysfunction and the 4th stage by a heavy motor deficit.

MRI is the examination of choice, and helps in the positive diagnosis of the SEDA and search of the initial infection site. Spinal CT myelogram has a similar sensitivity to MRI but entails a significant risk of spread of infection. ${ }^{6}$ 


\section{Joulali et al}
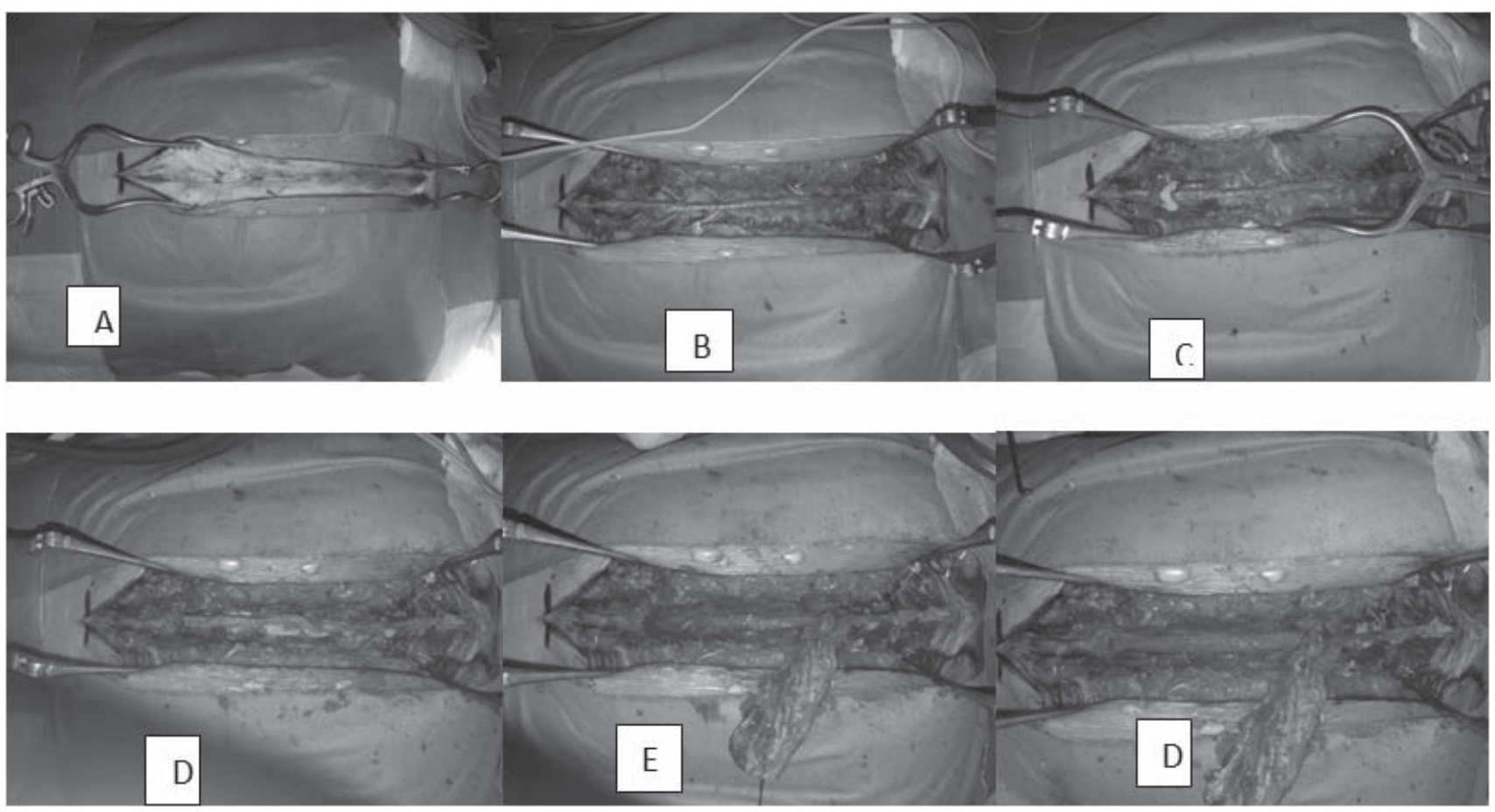

Figure 2 : Different operative stages of laminotomy : (a) skin incision (b) dissection of paravertebral muscles (c) cutting of interspinous ligament of T8-T9 and purulent collection (D) : T4-T8 lamina cutting (E) : visualization of dural sleeve with associated epidural collection (D) Final view after removal of purulent discharge.

SEDA is a medico-surgical emergency, early treatment based on antibiotics for (4-6 weeks) and a surgical intervention for compression is essential for a good functional prognosis. Surgical treatment entails emergency evacuation of the pus with decompression of the spinal cord and nerve roots. In the presence of paraparesis, the outcome depends on the time that elapses from its onset to surgery.The longer the lapse the greater is the usual long term legacy. The appearance of a motor neurological deficit exceeding the $36 \mathrm{~h}$ generally entails poor prognosis for functional recovery. ${ }^{7}$

\section{Conclusion:}

The SEDA is a rare pathology, most often seen in a context of immunosuppression. The clinical picture is nonspecific and requires biological and radiological investigations. The therapeutic treatment must be started early for good functional and vital prognosis. The appreciable neurological recovery seen in some patients reflects the value of prompt diagnosis and early treatment. The key to successful management is early diagnosis, which requires that involved clinicians consider the diagnosis. Repeated spinal and neurological examinations are essential in any patient with an unknown focus of infection and when there is spinal pain or tenderness full investigation is warranted. The increasing availability of MRI may mean that earlier diagnosis and lower morbidity from this condition should become a reality in the near future.

\section{References:}

1. Martin RJ, Yuan HA. Neurosurgical care of spinal epidural, subdural, and intramedullary abscesses and arachnoiditis. Orthop Clin North Am 27:p 125136, 1996.

2. Chao D, Nanda A. Spinal epidural abscess: a diagnostic challenge. Am Fam Physician 65: 13411346, 2002.

3. aker AS, Ojemann RG, Swartz MN, Richardson EP Spinal epidural abscess. N Engl JMed 197 293:463468, 1975.

4. Sendi P, Bregenzer T, Zimmerli W. Spinal epidural abscess in clinical practice. QJM 101:1-12, 2008.

5. Heusner AP. Nontuberculous spinal epidural infections. N Engl J Med. 1948;239:845-54, 1948.

6. Tung G, Yim J, Mermel L, Philip L, Rogg J. Spinal epidural abscess: correlation between MRI findings and outcome. Neuroradiology. 41(12):904-9. 1999.

7. Abderrazzak El Saqui, Mohamed Aggouri, Mohamed Benzagmout, Khalid Chakour,1 et Mohamed El Faiz Chaoui Une urgence médico-chirurgicale rare: l'abcès épidural rachidien (à propos de 03 cas) Pan Afr Med J. 26: 145, 2017. 
8. Rahman, M.A., Chaurasia, B.K., Hossain, M.A., Habib, S. and Barua, K.K. Very rare upperdorsal intramedullary epidermoid with paraplegia. a case report. Neuroimmunol Neuroinflammation 2018;5:14, 2018.

9. Baker AS, Ojemann RG, Swartz MN, Richardson Jr EP. Spinal epidural abscess. New England Journal of Medicine.;293(10):463-8. 1975 Sep 4.

10. Hlavin ML, Kaminski HJ, Ross JS, Ganz E. Spinal epidural abscess: a ten-year perspective. Neurosurgery. 1;27(2):177-84. 1990 Aug.

11. Darouiche RO. Spinal epidural abscess. New England Journal of Medicine. 9;355(19):2012-20, 2006 Nov.

12. Reihsaus E, Waldbaur H, Seeling W. Spinal epidural abscess: a meta-analysis of 915 patients. Neurosurgical review. 1;23(4):175-204, 2000 Dec.
13. Darouiche RO, Hamill RJ, Greenberg SB, Weathers SW, Musher DM. Bacterial spinal epidural abscess. Review of 43 cases and literature survey. Medicine. 71(6):369-85, 1992 Nov.

14. Rigamonti D, Liem L, Sampath $P$, Knoller N, Numaguchi Y, Schreibman DL, Sloan MA, Wolf A, Zeidman S. Spinal epidural abscess: contemporary trends in etiology, evaluation, and management. Surgical neurology. 1;52(2):189-97, 1999 Aug.

15. Wang LP, Hauerberg J, Schmidt JF. Incidence of spinal epidural abscess after epidural analgesia. Anesthesiology. 1;91(6):1928-36, 1999 Dec.

16. Del Curling O, Gower DJ, McWhorter JM. Changing concepts in spinal epidural abscess: a report of 29 cases. Neurosurgery. 1;27(2):185-92, 1990 Aug. 